\title{
ACQUISITION OF MAGNETIC DIRECTIONAL PREFERENCE IN HATCHLING LOGGERHEAD SEA TURTLES
}

\author{
KENNETH J. LOHMANN AND CATHERINE M. FITTINGHOFF LOHMANN \\ Department of Biology, University of North Carolina, Chapel Hill, NC 27599, USA
}

Accepted 6 January 1994

\begin{abstract}
Summary
During their natal migration, hatchling loggerhead sea turtles (Caretta caretta L.) establish courses towards the open ocean and maintain them after swimming beyond sight of land. Laboratory experiments have demonstrated that swimming hatchlings can orient using the earth's magnetic field. For the magnetic compass to function in guiding the offshore migration, however, hatchlings must inherit or acquire a magnetic directional preference that reliably leads them towards the open sea.

On land, hatchlings find the ocean using light cues associated with the seaward horizon. To determine whether turtles might acquire a preference for a specific magnetic direction on the basis of such cues, we studied the magnetic orientation of turtles initially exposed to light from either magnetic east or west. Hatchlings that had been exposed to light in the east subsequently oriented eastward when tested in darkness, whereas those that had been exposed to light in the west swam westward. Reversing the magnetic field resulted in a corresponding shift in orientation, indicating that the turtles were orienting to the ambient magnetic field.

These results demonstrate that light cues can set the preferred direction of magnetic orientation by loggerhead hatchlings. We therefore hypothesize that hatchlings initially establish a seaward course using visual cues available on or near land, then maintain the course using magnetic cues as they migrate into the open sea.
\end{abstract}

\section{Introduction}

At the beginning of their natal migration, hatchling sea turtles scramble from their nests to the ocean, enter the water and quickly establish courses towards the open sea. As turtles distance themselves from shore, they adopt headings resembling those they followed while crossing the beach (Ireland et al. 1978). Such bearings are maintained even after hatchlings have swum beyond sight of land (Frick, 1976).

Although the headings of hatchlings on the beach and at sea are similar, the cues used to maintain orientation in each case apparently are not. Hatchlings on a beach find the ocean by moving towards the bright seaward horizon and away from the dark elevated silhouettes of vegetation and dunes (Limpus, 1971; Salmon et al. 1992; Witherington, $1992 a$ ). Such visual cues, however, are not available to turtles after they have migrated a short distance from shore.

Key words: magnetic, orientation, magnetoreception, sea turtle, Caretta caretta. 
Recent experiments have demonstrated that two species of sea turtles, the loggerhead (Caretta caretta L.) and the leatherback (Dermochelys coriacea L.), can orient to the earth's magnetic field (Lohmann, 1991; Lohmann and Lohmann, 1993). If the magnetic compass functions during the offshore migration, however, turtles must somehow correctly ascertain the magnetic direction in which the open ocean lies.

Hatchlings might establish an appropriate magnetic course in several ways (Lohmann, 1991). One possibility is that hatchlings emerge from their eggs or nests already possessing a preference for orientation towards the appropriate magnetic direction. Alternatively, hatchlings might acquire a magnetic directional preference as they cross the beach or swim away from land. Thus, hatchlings might initiate a seaward course using orientation cues available on the beach or near shore, then 'transfer' the course to the magnetic compass.

To determine whether hatchlings might acquire a magnetic directional preference on the basis of cues encountered after hatching, we studied the magnetic orientation of loggerheads initially exposed to light from one of two different directions. The results indicate that the direction of light initially encountered by turtles determined the magnetic direction towards which they subsequently oriented in darkness. Thus, visual cues associated with the seaward horizon may play an important role in setting the magnetic preference of hatchling turtles as they leave their natal beach.

\section{Materials and methods}

Animals

Hatchling loggerheads were obtained from a beach hatchery located approximately $30 \mathrm{~km}$ south of Fort Pierce, Florida, USA. The hatchery consisted of nests relocated from nearby beaches unsafe for hatchlings. All nests were moved to the hatchery within $24 \mathrm{~h}$ of natural deposition, positioned in a row parallel to the sea about $10 \mathrm{~m}$ above the spring high tide line, and marked by a stake indicating the date that the eggs had been laid. The hatchery beach faced east-northeast, typical of the shoreline in the area, and was commonly used by loggerheads as a nesting site.

Nests were examined daily. When a depression formed in the sand above a nest (indicating that turtles had hatched and an emergence would probably occur that night), we gently dug in the sand and removed several hatchlings. Hatchlings were immediately placed into light-tight Styrofoam containers and transported within $45 \mathrm{~min}$ to a laboratory, where they were maintained in complete darkness in lightproof enclosures. Hatchlings were tested a single time on their first, second or third night in captivity. Turtles kept in the laboratory for more than one night were maintained in darkness in Styrofoam coolers containing damp sand or paper towels.

\section{Orientation arena and data acquisition}

Hatchlings were tested in a circular, water-filled arena described previously (Lohmann, 1991). In each trial, a hatchling was placed into a nylon-lycra harness that encircled the turtle's carapace without impeding swimming (Salmon and Wyneken, 1987). The harness was connected by a short monofilament line to a lever-arm, which was mounted 


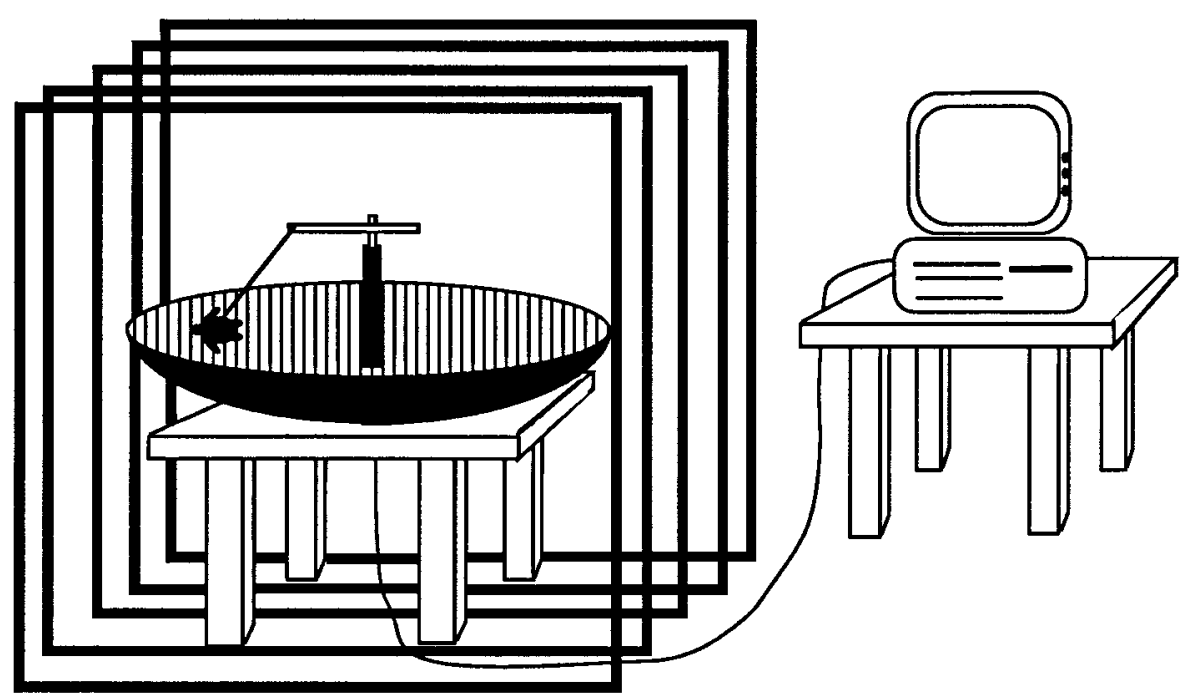

Fig. 1. The orientation arena. Hatchlings were tethered to a rotatable lever-arm mounted on a $360^{\circ}$ rheostat in the center of a water-filled, fiberglass satellite dish. The rheostat was wired to a computer in an adjacent room so that the orientation of a hatchling swimming in complete darkness could be continuously monitored. The orientation arena was surrounded by a Rubens cube coil with each side measuring $130 \mathrm{~cm}$.

on a $360^{\circ}$ rheostat positioned on a post in the center of an inverted satellite dish (Fig. 1). The lever arm was free to rotate within the horizontal plane and could easily be pulled clockwise or counterclockwise by a swimming hatchling. The arm thus tracked the direction towards which the hatchling swam.

The rheostat on which the lever arm rested was part of a circuit containing a $3 \mathrm{~V}$ d.c. power source. Thus, each orientation of the lever arm resulted in a different resistance through the circuit. A computer in an adjacent room recorded the orientation of the turtle (accurate to $\pm 2^{\circ}$ ) every $30 \mathrm{~s}$. Immediately before each experiment, the system was calibrated by obtaining readings for a series of known compass directions.

\section{Control of the ambient magnetic field}

The satellite dish and supporting table were enclosed by a Rubens cube coil (Rubens, 1945) whose sides measured $130 \mathrm{~cm}$ (Fig. 1). The coil was used to control the direction of the magnetic field around the satellite dish. When connected to a d.c. power source, the coil generated a field approximately twice as strong as the horizontal component of the geomagnetic field and opposite in direction. Thus, turtles could be exposed to a reversed magnetic field in which magnetic north was shifted $180^{\circ}$ with respect to geomagnetic north.

Measurement with a Schonstedt single-axis digital fluxgate magnetometer (model DM $2220 \mathrm{R}$ ) indicated that, with the coil on, the horizontal component of the reversed field ranged from 23000 to $26000 \mathrm{nT}$ in the circular zone where the turtles swam, similar to the horizontal component of about $25000 \mathrm{nT}$ measured in the arena when the coil was off. The vertical component of the earth's field was not altered. 


\section{Testing procedure}

The coil, satellite dish and supporting table were positioned in the center of a light-tight room. Experiments began shortly after sunset and continued throughout the night, the time when virtually all loggerhead hatchlings emerge from their nests and enter the ocean (Witherington et al. 1990). All experiments were terminated by $08: 00 \mathrm{~h}$. One to four hatchlings were tested each night.

Turtles were randomly assigned to one of four groups. Each hatchling in the first group was tethered in the orientation arena and presented with a dim light (Lohmann, 1991) in magnetic east for $1 \mathrm{~h}$. The light was then turned off, and the orientation of the turtle was monitored as it swam in darkness in the geomagnetic field. Hatchlings in the second group were treated identically, except that the Rubens coil was turned on when the light was turned off, so that turtles swam in darkness in a reversed magnetic field. The third group was exposed to a light in magnetic west for $1 \mathrm{~h}$, then tested in darkness in the earth's magnetic field. The fourth group was tethered in the arena in complete darkness and tested without exposure to light cues. In all trials, data collection began $70 \mathrm{~min}$ after the turtle had been placed into the arena (i.e. $10 \mathrm{~min}$ after the light had been turned off in the three treatments with light).

To ensure that no light was present while data were being recorded, all electronic equipment (e.g. computers and power strips) capable of producing light was located in an adjacent room. As an additional precaution, an observer occasionally sat silently beside the coil while experiments were in progress. Following dark adaptation of $1 \mathrm{~h}$ or longer, three different observers failed to perceive any light leaks or bioluminescence despite systematic searches.

\section{Orientation behavior and data analysis}

Tethered hatchlings tested in darkness alternate between two distinct patterns of behavior: circling and oriented swimming (Lohmann, 1991). Circling behavior is characterized by continuous movement around the perimeter of the tank, whereas turtles engaged in oriented swimming maintain relatively constant courses towards a specific direction. Oriented swimming periods were defined previously as periods of $3 \mathrm{~min}$ or longer during which a turtle remains in a single $90^{\circ}$ sector (Lohmann, 1991).

While circling, turtles spend equal amounts of time in all parts of the arena and do not manifest directional preferences. Analyses were therefore based on oriented swimming periods using procedures described previously (Lohmann, 1991), except that (i) the accuracy of the orientation measurements in the present study was improved to $\pm 2^{\circ}$; (ii) measurements were taken every $30 \mathrm{~s}$ rather than every minute, and (iii) to obtain data more rapidly, each trial was terminated as soon as a hatchling had completed four oriented swimming periods. Those few hatchlings (approximately 10\%) that failed to complete four oriented swimming periods in $4 \mathrm{~h}$ were replaced with other turtles.

At the completion of all experiments, the mean angles of turtles in the four treatments were analyzed to determine (1) whether each group was significantly oriented; (2) whether the distributions of mean angles differed significantly in the two field conditions for hatchlings initially exposed to the east light, and (3) whether the distributions of mean angles differed between groups exposed to light from opposite directions. 


\section{Results}

As in previous studies (Salmon and Wyneken, 1987; Lohmann, 1991; Light et al. 1993), hatchlings swam vigorously towards the light $\left( \pm 45^{\circ}\right)$ while it was on, regardless of its position (east or west). Hatchlings tested in darkness in the geomagnetic field after exposure to the east light were non-randomly oriented ( $r=0.67, z=5.78, P<0.002$, Rayleigh test) with a mean angle of $76^{\circ}$ (Fig. 2A). In contrast, hatchlings exposed to the east light but tested in darkness in the reversed field were non-randomly oriented with a mean angle of $245^{\circ}(\mathbf{r}=0.61, z=2.94, P<0.05$, Rayleigh test; Fig. 2B $)$. The two distributions are significantly different $\left(U^{2}=0.355, P<0.001\right.$, Watson test), indicating that the ambient magnetic field influenced the orientation of the turtles under the experimental conditions.

In contrast to the easterly orientation of hatchlings initially exposed to the east light, turtles tested in darkness following exposure to a light in the west (Fig. 2C) oriented nonrandomly towards a west-southwesterly direction (mean angle $=231^{\circ}, \mathbf{r}=0.54, z=3.46$, $P=0.027$, Rayleigh test). The east-light (Fig. 2A) and west-light (Fig. 2C) geomagnetic field distributions are significantly different $\left(U^{2}=0.406, P<0.001\right.$, Watson test), indicating that the position of the light initially encountered by hatchlings influenced the magnetic direction towards which they subsequently swam.

Hatchlings tested in darkness without any exposure to light were not significantly oriented as a group (mean angle $=152^{\circ}, \mathbf{r}=0.23, z=0.94, P>0.36$; Fig. 2D).

\section{Discussion}

Hatchling loggerheads initially exposed to a light in the magnetic east subsequently oriented eastward in darkness when tested in the geomagnetic field (Fig. 2A). In contrast, turtles exposed to the east light but tested in darkness in a reversed field oriented in approximately the opposite direction (Fig. 2B). These results closely parallel those obtained by Lohmann (1991) and confirm that the non-random orientation observed in darkness under the present experimental conditions was mediated by magnetic field detection.

Whereas hatchlings exposed to the east light subsequently swam towards magnetic east in darkness (Fig. 2A), turtles exposed to a light in magnetic west oriented approximately westward (Fig. 2C). These results indicate that the position of light cues can influence the magnetic course that hatchlings adopt.

\section{Establishment of a magnetic directional preference}

The results demonstrate that hatchlings can transfer a course initiated using a nonmagnetic cue to a course mediated by magnetic compass orientation. A similar transfer of directional information may normally occur during the offshore migration.

Hatchlings on a beach initially locate the ocean using visual cues (reviewed by Witherington, 1992a). Because the ocean reflects more light than does the land, and because most nesting beaches are backed by dunes or vegetation, the seaward horizon is both brighter and lower in elevation than the landward horizon. By moving towards the lower and brighter horizon, hatchlings reliably find the sea (Limpus, 1971; Salmon et al. 
1992). Thus, one possible interpretation of our data is that hatchlings (i) determine the direction of the open ocean while on or near shore using light or horizon cues; (ii) establish an appropriate magnetic directional preference on this basis, and (iii) subsequently use this acquired directional preference to maintain orientation as they migrate into the open sea.

\section{Directional plasticity of offshore orientation}

The only hatchlings that were not significantly oriented as a group were those tested without prior exposure to light cues (Fig. 2D). This result is consistent with the hypothesis that hatchlings emerge from their nests without a preferred magnetic direction and must subsequently acquire one.

Establishing a magnetic preference on the basis of environmental features that indicate the local seaward direction may endow hatchlings with the flexibility needed to reach the open ocean from any nesting beach. Such plasticity may be advantageous, as the topography of coastlines used by turtles for nesting is sometimes irregular, and the offshore direction may vary considerably at different sites. Loggerhead hatchlings emerging on the east coast of Florida, for example, must swim eastward to reach open water, whereas hatchlings that emerge on the west coast of Florida must swim west. To establish appropriate offshore headings from any location, hatchlings might need only to determine the direction of the open ocean visually and subsequently maintain an appropriate seaward bearing using their magnetic compasses.

\section{Multiple orientation cues}

After entering the ocean, hatchling sea turtles may use at least two different orientation cues to direct their seaward migration (Lohmann, 1992). Hatchlings initially orient by swimming into waves (Salmon and Lohmann, 1989; Lohmann et al. 1990; Lohmann and Lohmann, 1992). As waves enter shallow water and approach shore, the propagation direction is refracted until it is nearly perpendicular to the beach (Denny, 1988). Thus, swimming into waves initially results in a seaward course.

Farther from land, where waves no longer provide a reliable indicator of offshore direction, hatchlings have been observed maintaining seaward courses seemingly independent of wave direction (Witherington, 1992b). We hypothesize that magnetic orientation supplants or modulates wave orientation at this later stage of the migration. The magnetic compass might also function continuously as a 'backup' system throughout the migration for use when waves and/or other cues are not available (Lohmann, 1991).

In addition to guiding orientation, multiple cues could be involved in setting magnetic directional preferences. Because wave direction near shore provides a reliable indicator of offshore direction, turtles might normally use wave direction, instead of (or in addition to) visual cues, to set a magnetic preference.

Yet another possibility is that turtles need only to maintain a consistent course for a short time (perhaps either on land or in water) to acquire a magnetic preference. Additional experiments will thus be required to determine whether the preference is normally established on the basis of a specific environmental cue or whether the experience of simply maintaining a course (no matter how) is sufficient. 
East light, geomagnetic field

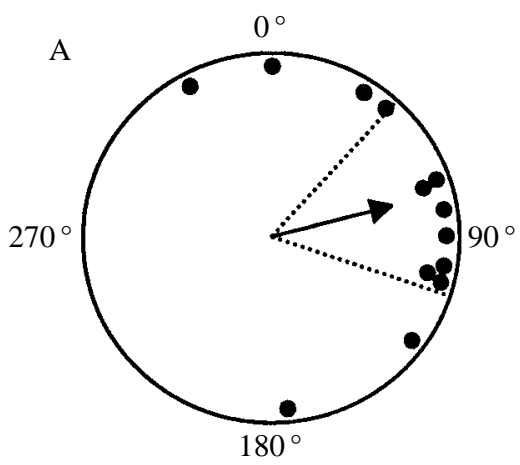

West light, geomagnetic field

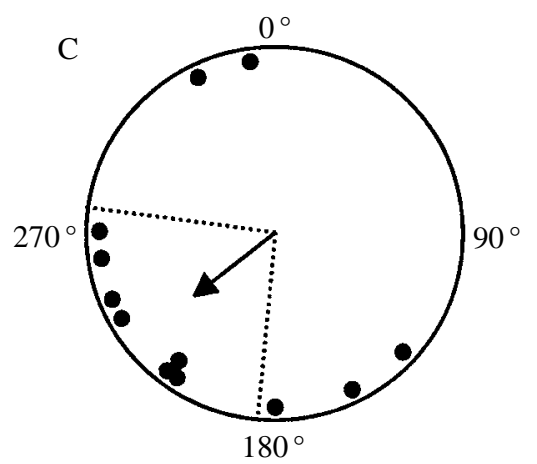

East light, reversed field

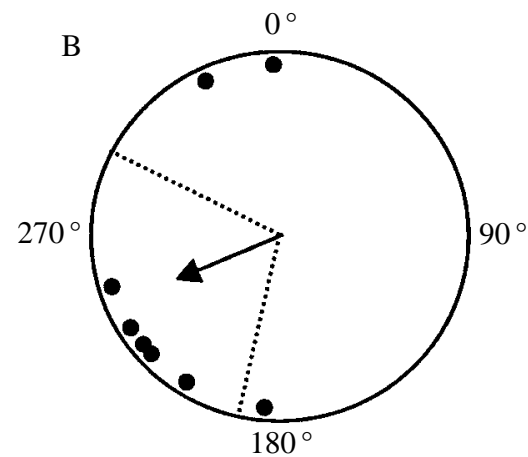

No light, geomagnetic field

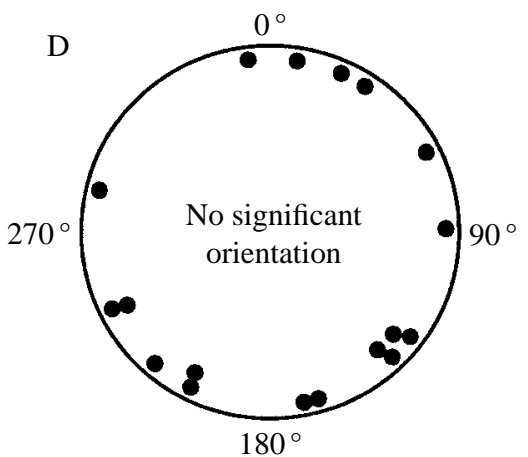

Fig. 2. Results of experiments under the four conditions. Each data point represents the mean angle of orientation for a single hatchling. Arrows indicate the mean angle and mean vector for each group; arrow length is proportional to mean vector length, with the perimeter of the circle representing $\mathbf{r}=1.0$. Dashed lines indicate the $95 \%$ confidence interval for each mean angle (Batschelet, 1981). (A) Results from turtles exposed to the east light and then tested in the geomagnetic field in complete darkness. The turtles were significantly oriented (mean angle $=76^{\circ}, \mathbf{r}=0.67, z=5.78, P<0.002$, Rayleigh test). Analysis with the $V$-test (Batschelet, $1981)$ using the predicted direction of $90^{\circ}$ also yielded significance $(P<0.001)$. (B) Results from turtles exposed to the east light and then tested in a reversed magnetic field in complete darkness. Turtles were significantly oriented (mean angle $=245^{\circ}, \mathbf{r}=0.61, z=2.94, P<0.05$, Rayleigh test). Analysis with the $V$-test using the predicted direction of $270^{\circ}$ also yielded significance $(P<0.02)$. (C) Results from turtles exposed to a west light and then tested in the geomagnetic field in complete darkness. Turtles were significantly oriented (mean angle $=231^{\circ}, \mathbf{r}=0.54, z=3.46, P=0.027$, Rayleigh test). (D) Results from turtles tested in darkness without prior exposure to light cues. The turtles were not significantly oriented as a group $(\mathbf{r}=0.23, z=0.94, P>0.36$, Rayleigh test $)$.

Regardless of these considerations, the results demonstrate that environmental features that hatchlings encounter soon after emerging from their nests can influence the preferred direction of magnetic orientation. Thus, the experience of a hatchling early in its migration may influence its subsequent orientation behavior. Further investigations on 
sea turtle hatchlings appear likely to reveal additional interactions between orientation systems, as well as insight into the ontogeny of directional preferences and the integration and use of multiple directional cues.

We thank Jay Callaway for developing the data acquisition system and Jeanette Wyneken, Mike Salmon, Lori Wollerman and Beth Manning for critically reading drafts of the manuscript. We are also indebted to the Florida Power and Light Company for permitting us to establish a sea turtle hatchery on their property, to Erik Martin and Bob Ernest for relocating turtle nests, and to the Harbor Branch Oceanographic Institution for providing laboratory space. Research on a threatened species was authorized under Florida DNR special permits TP 065 and TP 073 and was supported by NSF grants IBN9120338 and BNS-87-07173.

\section{References}

BatsChelet, E. (1981). Circular Statistics in Biology. London: Academic Press.

Denny, M. W. (1988). Biology and the Mechanics of the Wave-swept Environment. Princeton, New Jersey: Princeton University Press.

FRICK, J. (1976). Orientation and behaviour of hatchling green sea turtles (Chelonia mydas) in the sea. Anim. Behav. 24, 849-857.

Ireland, L. C., Frick, J. A. AND WingATE, D. B. (1978). Nighttime orientation of hatchling green turtles (Chelonia mydas) in open ocean. In Animal Migration, Navigation and Homing (ed. K. SchmidtKoenig and W. T. Keeton), pp. 420-429. New York: Springer-Verlag.

Light, P., SAlmon, M. AND Lohmann, K. J. (1993). Geomagnetic orientation of loggerhead sea turtles: evidence for an inclination compass. J. exp. Biol. 182, 1-10.

LimPUS, C. (1971). Sea turtle ocean finding behaviour. Search 2, 385-387.

LoHMAnN, K. J. (1991). Magnetic orientation by hatchling loggerhead sea turtles (Caretta caretta). J. exp. Biol. 155, 37-49.

LoHMANN, K. J. (1992). How sea turtles navigate. Scient. Am. 266, 100-106.

LOHMANN, K. J. AND LOHMANn, C. M. F. (1992). Orientation to oceanic waves by green turtle hatchlings. J. exp. Biol. 171, 1-13.

Lohmann, K. J. And Lohmann, C. M. F. (1993). A light-independent magnetic compass in the leatherback sea turtle. Biol. Bull. mar. biol. Lab., Woods Hole 185, 149-151.

Lohmann, K. J., Salmon, M. And Wyneken, J. (1990). Functional autonomy of land and sea orientation systems in sea turtle hatchlings. Biol. Bull. mar. biol. Lab., Woods Hole 179, 214-218.

RubEns, S. M. (1945). Cube-surface coil for producing a uniform magnetic field. Rev. Sci. Instr. 16, 243-245.

SALMON, M. AND Lohmann, K. J. (1989). Orientation cues used by hatchling loggerhead sea turtles (Caretta caretta) during their offshore migration. Ethology 83, 215-228.

SALMON, M. AND WyNEKEN, J. (1987). Orientation and swimming behavior of hatchling loggerhead turtles (Caretta caretta L.) during their offshore migration. J. exp. mar. Biol. Ecol. 109, 137-153.

SAlmon, M., WynekEn, J., Fritz, E. AND LuCAS, M. (1992). Seafinding by hatchling sea turtles: role of brightness, silhouette and beach slope as orientation cues. Behaviour 122, 56-77.

WitheRINGTON, B. E. (1992a). Sea-finding behavior and the use of photic orientation cues by hatchling sea turtles. PhD dissertation, University of Florida, Gainesville, Florida, USA.

Witherington, B. E. (1992b). Observations of hatchling loggerhead turtles during the first few days of the lost year(s). In Proceedings of the Twelfth Annual Sea Turtle Symposium. NOAA Technical Memorandum. (in press).

Witherington, B. E., Bjorndal, K. A. And McCabe, C. M. (1990). Temporal pattern of nocturnal emergence of loggerhead turtle hatchlings from natural nests. Copeia 4, 1165-1168. 